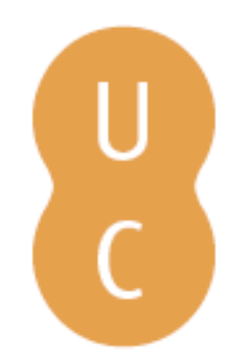

\title{
nommalina
}

\section{A heterogeneidade política e jurídica como resposta ao desafio da diversidade na União Europeia}

\author{
Autor(es): $\quad$ Enes, Graça \\ Publicado por: Imprensa da Universidade de Coimbra \\ URL \\ persistente: URI:http://hdl.handle.net/10316.2/47431 \\ DOI: $\quad$ DOl:https://doi.org/10.14195/978-989-26-1524-0_7 \\ Accessed : $\quad$ 26-Apr-2023 15:01:01
}

A navegação consulta e descarregamento dos títulos inseridos nas Bibliotecas Digitais UC Digitalis, UC Pombalina e UC Impactum, pressupõem a aceitação plena e sem reservas dos Termos e Condições de Uso destas Bibliotecas Digitais, disponíveis em https://digitalis.uc.pt/pt-pt/termos.

Conforme exposto nos referidos Termos e Condições de Uso, o descarregamento de títulos de acesso restrito requer uma licença válida de autorização devendo o utilizador aceder ao(s) documento(s) a partir de um endereço de IP da instituição detentora da supramencionada licença.

Ao utilizador é apenas permitido o descarregamento para uso pessoal, pelo que o emprego do(s) título(s) descarregado(s) para outro fim, designadamente comercial, carece de autorização do respetivo autor ou editor da obra.

Na medida em que todas as obras da UC Digitalis se encontram protegidas pelo Código do Direito de Autor e Direitos Conexos e demais legislação aplicável, toda a cópia, parcial ou total, deste documento, nos casos em que é legalmente admitida, deverá conter ou fazer-se acompanhar por este aviso.

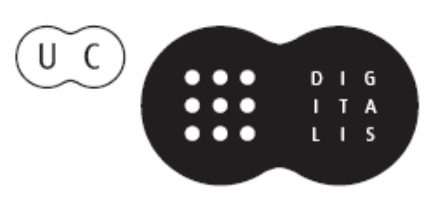


JOSÉ MANUEL PUREZA JOSÉ JUSTE RUIZ (COORDS.)
IMPRENSA DA

UNIVERSIDADE

DE COIMBRA

COIMBRA

UNIVERSITY

PRESS
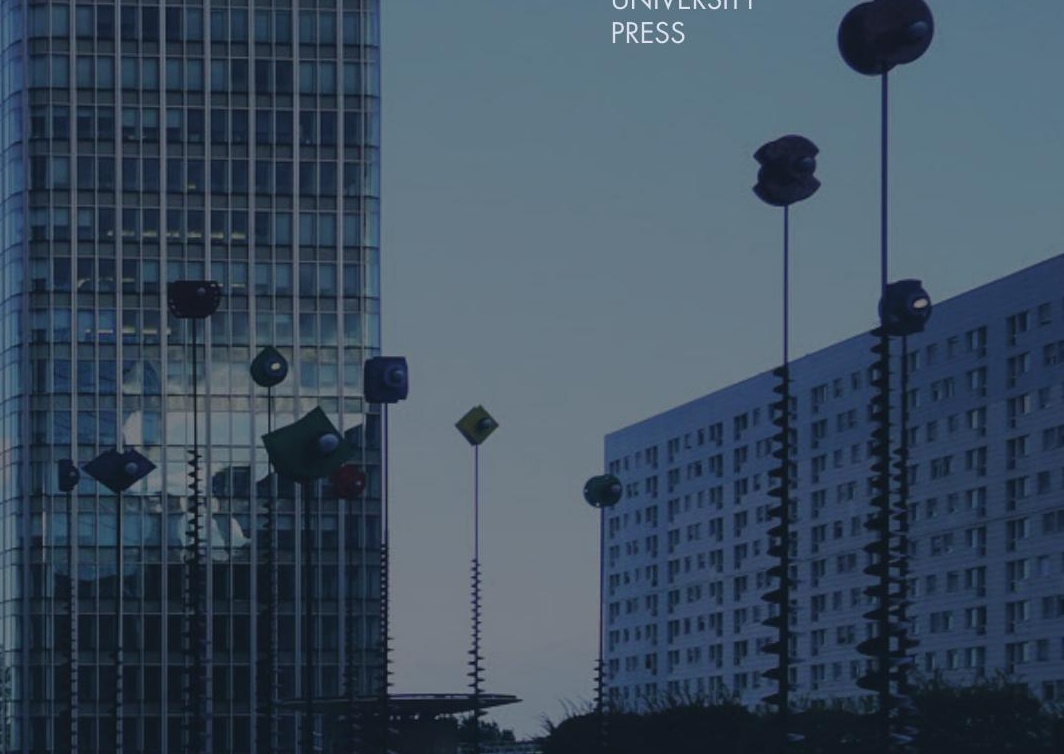

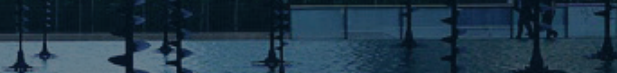

OS ESTADOS

EA ORDEM

INTERNACIONAL

CONTEMPORANEA

ATAS DO V ENCONTRO LUSO-ESPANHOL DE Professores de Direito internacional e RELAÇÕES INTERNACIONAIS 


\title{
A HETEROGENEIDADE POLÍTICA E JURÍDICA COMO RESPOSTA AO DESAFIO DA DIVERSIDADE NA UNI ÃO EUROPEIA
}

\author{
Graça Enes
}

\section{O processo de integração europeia como homogeneização progressiva}

A atual União Europeia é o produto de um processo de unificação política e jurídica que se desenvolveu ao longo das últimas seis décadas. O seu ímpeto e sucesso residiriam na eliminação ou superação da heterogeneidade. Este caminho far-se-ia de modo suave, por spillover, mas sem previsão de grandes escolhos. Porém, pode concluir-se hoje que essa homogeneização foi em parte obnubilação.

Entre os Estados fundadores a heterogeneidade não era radical. Todos eram sobreviventes de uma recente e trágica experiência de guerra, democracias empenhadas assentes em governos democrata-cristãos ou social-democratas que partilhavam um ideário europeu forjado numa ancestral herança cultural assumida como comum e na recente resistência ao totalitarismo. As diferentes preferências políticas e económicas dominantes cabiam num projeto liberal de mercado comum regulado à escala europeia ${ }^{1}$, que garantiria o cresci-

${ }^{1}$ A margem da extrema direita política era irrelevante; a margem política esquerda foi secundarizada ou apagada pela lógica bipolar da guerra fria. 
mento económico indispensável para suportar os Estados-providência nacionais. A missão salvífica da integração europeia para os destroçados Estados nacionais europeus foi já apontada (Milward, 1992).

Por outro lado, o desígnio federador delineava-se de modo mediato e com contornos vagos que não suscitavam divergências significativas do lado de cá do Canal da Mancha.

O fracasso da Comunidade Europeia de Defesa e da sua 'irmã' Comunidade Política Europeia são o primeiro tropeção na heterogeneidade das preferências políticas, com o confronto deliberado entre a 'Europa das nações' e o modelo supranacional, com uma réplica posterior na afamada 'crise da cadeira vazia'. Este desafio vai ser superado pelo adiamento indefinido do projeto de unificação política. $\mathrm{O}$ intergovernamentalismo político parece reinar afinal, o que não impediu uma diluição jurídica supranacional da heterogeneidade.

A partir de 1957, a Comunidade Económica Europeia vai impor uma unificação progressiva da regulação económica e por essa via vem a homogeneizar as preferências político-económicas nacionais. A primeira liberalização do mercado até 1968 não exclui a tónica intervencionista do capitalismo social de mercado de feição keynesiana. O relançamento posterior às crises da década de 70 do século XX generaliza, com a sua tónica desreguladora e neoreguladora, o capitalismo liberal anti-intervencionista. $\mathrm{O}$ 'mercado interno 1993' era o grande desígnio que recolocaria a Europa e os seus Estados na senda do crescimento. Tudo parecia bem no 'reino das Comunidades Europeias', agora um novo tipo de ente político - o 'Estado regulador' (Majone, 1998). A moeda única seria o zénite do processo de integração económica, mesmo que tivesse sido necessário 'martelar' os critérios de convergência macroeconómica para que integrasse economias tão heterogéneas.

O Direito e a instituição competente para a respetiva garantia - o Tribunal de Justiça - foram protagonistas deste processo. A harmonização das diretivas foi muitas vezes uniformização total. As insuficiências 
das competências atribuídas não foram obstáculo ${ }^{2}$. O Tribunal assegurou que as liberdades do mercado comum não eram defraudadas por idiossincrasias nacionais, fossem elas técnicas de produção tradicionais ${ }^{3}$, tendências dos consumidores internos ${ }^{4}$ ou outras. $\mathrm{O}$ efeito direto e o primado foram os princípios constitucionais de uma unidade uniforme. Em suma, o intergovernamentalismo político, 'paradoxalmente', não tolheu o supranacionalismo normativo (Weiler, 1982).

Com o 'Compromisso do Luxemburgo', em 1966, a superação das objeções nacionais resultantes da heterogeneidade dos respetivos interesses, que se tornavam mais relevantes à medida que o progresso da integração avançava, apartou-se do modelo supranacional da maioria nas deliberações do Conselho em favor de um consenso forjado numa proto-unanimidade - a continuação da "negociação até se alcançar uma solução razoável" -, justificada com a invocação de um 'interesse vital'. Recusada pelo Tribunal como parte do acervo, pairou durante décadas sobre o processo decisório e foi politicamente aceite pelos Estados, ainda que desde 1984 não se registe a sua utilização com sucesso. Algumas vezes foi ultrapassada por outro método, frequente desde a Comissão Delors, o 'package deal'; recorde-se a negociação da liberalização do setor têxtil no Uruguay Round, em 1992, e a compensação financeira obtida pelo Estado português. A generalização da maioria qualificada retirou-lhe relevo, mas manteve-se a lógica da negociação permanente e multinível a que obedece na realidade o funcionamento da União.

O 'Compromisso de Ioannina', em 1994, foi um sucedâneo que encontra eco ainda no Tratado de Lisboa com a extensão do regime

\footnotetext{
${ }^{2}$ Pela via da cláusula do então artigo $235 .^{\circ}$ do Tratado da Comunidade Económica Europeia ou da jurisprudência sucessiva do Tribunal desde o Acórdão de 31.03.1971, AETR, Proc. 22/70.

3 Acórdão de 12.3.1987, Comissão c. Grécia, Proc. 178/84; Acórdão de 12.3.1987, Comissão c. Alemanha, Proc. 178/84 ('lei da pureza da cerveja').

${ }^{4}$ Acórdão de 20.2.1979, Rewe-Zentral AG, Proc. 120/78 ('Cassis de Dijon').
} 
de deliberação transitório. Na verdade, o 'espírito do Luxemburgo' ressurge desde o Tratado de Amesterdão em múltiplas soluções em que a invocação de um interesse fundamental de um EM suspende a deliberação e a eleva para um patamar de discussão superior o Conselho Europeu - e conduz a decisões que vinculam apenas alguns Estados membros (v.g. a cooperação judicial - artigos 82. ${ }^{\circ}$, n. ${ }^{\circ} 3$ e $86 .^{\circ}$, n. ${ }^{\circ} 3$ do TFUE).

O sucesso da realização da união aduaneira, em 1968, propiciou a vontade política manifestada na Cimeira de Haia de 1969 sob o lema 'acabamento, alargamento, aprofundamento'5. É certo que o aprofundamento substantivo só veria a luz do dia com a primeira revisão dos Tratados pelo Ato Único Europeu de 1985 e, principalmente, com o Tratado de Maastricht, em 1991.

Neste tratado, o aprofundamento da União Europeia foi estruturalmente heterogéneo: uniforme na política monetária e na política financeira macroeconómica; débil na união económica; nulo na fiscalidade e federalização financeira; intergovernamental e limitado na PESC e nos assuntos internos e de justiça.

\section{Desafios paradoxais}

\subsection{Aprofundamento e crescente heterogeneidade trazida pelos alargamentos}

A ambição do projeto era também o da realização histórica e geográfica da 'Europa'. O convite aberto aos Estados europeus apresentado por Robert Schuman foi sucessivamente respondido em ondas de novos Estados-membros em 1973, 1981, 1986, 1995, 2004/2007

5 Cf. Bulletin of the European Communities, N. ${ }^{\circ} 1,1970$. 
e 2013. Dos seis Estados fundadores tão similares chegamos a 28, da latitude boreal ao Mediterrâneo, do Atlântico ao Báltico. A diversidade política, cultural, histórica, económica foi exponenciada.

Os riscos da acrescida heterogeneidade foram percebidos. No primeiro alargamento, a preocupação principal foi a diluição do projeto integrador; o 'Relatório Tindemans' ${ }^{6}$ reconhecia-o; a 'Declaração da Identidade Europeia'7 relembrava o património comum, os interesses e o dinamismo da integração europeia. A 'euroesclerose' revelou-se numa década que começou com o ambicioso projeto de criar uma União até 1980 , incluindo uma união económica e monetária ${ }^{8}$, e decorreu como uma gestão corrente das políticas sem avanços políticos de nota. Nos alargamentos às jovens democracias do sul, a preocupação foi para os valores políticos e os direitos ${ }^{9}$. Estas beneficiaram de uma feliz conjugação com uma fase de 'euroentusiasmo', que se viveu em meados da década de 80 do século XX em torno da realização do mercado interno.

A heterogeneidade, percecionada sobretudo como sendo económica, seria superada por uma natural convergência resultante da eliminação dos 'custos da não Europa'10 O significativo alargamento aos PECO, em virtude da sua dimensão e do elevado impacto político-económico, foi antecedido da fixação de apertados critérios de adesão, políticos, económicos e jurídicos, no Conselho Europeu

${ }^{6}$ Cf. European Union. Report by Mr. Leo Tindemans, Prime Minister of Belgium, to the European Council», Bulletin CE, Sup. 1/76.

7 Cf. Bulletin of the European Communities, Déc. 1973, n. ${ }^{\circ}$ 12, pp. 127-130.

8 Cf. 'Relatório Werner', de 8/10/1970. Cf. Bull. CE, N. ${ }^{7}$, Sup., 1970.

9 EUROPEAN PARLIAMENT, COUNCIL, COMMISSION, Declaração Comum sobre a Democracia e Direitos Fundamentais, de 5/4/1977, JOCE C 103 de 27.4.1977, p. 1; Declaração sobre a Democracia dos Chefes de Estado e de governo reunidos no Conselbo, de 7 e 8.4.1978. Consultada em 22.11.2015, em http://aei.pitt.edu/1440/1/ Copenhagen_1978.pdf .

10 Cf. COMMISSION OF THE EUROPEAN COMMUNITIES, Europe 1992. The overall challenge ('Cechinni Report') SEC (88)524 final Brussels, 13 April 1988. Consultado a 22.11.2015 em http://aei.pitt.edu/3813/1/3813.pdf . 
de Copenhaga, em 21 e 22 de junho de 199311; além do reiterar dos valores e princípios afirmados anteriormente, salientam-se a explicitação do modelo económico de mercado e concorrência e o cumprimento estrito do acervo. E os novos Estados membros tiveram um regime de transição em relação a várias políticas (v.g. na PAC ou na livre circulação de trabalhadores) que os tratou como 'sócios de segunda'.

A prolongada reforma institucional iniciada com o Tratado de Nice foi a resposta para o desafio da heterogeneidade ao funcionamento das instituições, cuja eficiência e representatividade era alegadamente posta em causa por alargamentos sucessivos, em especial pelo último. A reponderação do número de deputados no PE e dos votos no Conselho traduziu o reconhecimento da heterogeneidade dos Estados-membros - muito grande, grandes, médio-grandes, médios, pequenos Estados; a diferente dimensão é refletida de modo mais diretamente proporcional na tomada de decisão. A multiplicação de regimes transitórios e excecionais torna o resultado de uma complexidade só acessível a 'iniciados' da mágica burocracia europeia.

\subsection{O fim do consenso tácito sobre a Europa}

Desde a década de 70, o debate sobre a criação da União Europeia vem sendo feito a espaços. Desde o 'Relatório Tindemans', de 1975, até ao 'Projeto Spinelli', de 1984, a principal realização política foi a eleição direta do PE, iniciada em 1979. Esta teve uma participação acima dos $60 \%$, número que se inverteu progressivamente e passou, na última eleição, a representar a abstenção (a participação na eleição de 2014 foi de 42,5\%).

11 Cf. Conclusões da Presidência. Consultado a 22.11.2015, em http://www.consilium.europa.eu/uedocs/cms_data/docs/pressdata/pt/ec/72926.pdf 
A criação da União Europeia pelo Tratado de Maastricht, entrado em vigor em 1993, foi o resultado de fatores pró-integracionistas e da nóvel heterogeneidade resultante do fim do bloco soviético.

O sucesso do lançamento do mercado interno e do mote da 'Europa sem fronteiras' impulsionou a criação da UEM, da nova cidadania da União e da cooperação judicial e policial. Esta, baseando-se na experiência internacional do acordo de Schengen, é a necessária contraface da liberdade de circulação prevista para 1993. A consciência das dificuldades de comunitarizar domínios arreigados em tradições e quadros constitucionais fundamentais limita a respetiva ambição e enquadra-a em flexíveis moldes de articulação intergovernamental aptos a respeitar a diversidade das políticas nacionais. A unanimidade era a regra; os seus instrumentos jurídicos não eram uniformizadores ('posição comum' e 'ação comum') e estavam isentos da fiscalização do Tribunal de Justiça. Tendo embora evoluído no sentido de uma comunitarização, a unanimidade ainda é a chave nestes novos domínios.

A cidadania europeia construiu-se em sentido inverso à tradicional cidadania nacional (direitos civis, direitos políticos e direitos sociais): os direitos económicos precederam os políticos, embora sob uma forma de liberdade cívica à europeia (a liberdade de circulação e de empreendimento). Apesar de densificada pela jurisprudência do Tribunal, que a eleva ao 'estatuto fundamental' dos nacionais dos $\mathrm{EM}^{12}$, não deixou de ser uma 'cidadania no papel', não representativa de um sentimento de identidade ou pertença europeia. Em 1950, entre os Estados fundadores da integração europeia, encontrava-se entre os cidadãos uma identificação com a 'Europa' e a esperança passava precisamente pelo projeto europeu. $\mathrm{O}$ primeiro transporte de produtos carboníferos que teve lugar sob a égide da CECA foi saudado efusivamente por milhares de pessoas. Havia uma identidade

12 Acórdão de 20.09.2001, 'Grzelczyk', Proc. C-184/99. 
europeia sem cidadania europeia. À medida que se desenvolveu a integração e que diversos direitos 'europeus' foram sendo reconhecidos aos nacionais dos EM essa identidade foi-se esbatendo.

Depois de ultrapassada a tragédia e com a recomposição dos Estados democráticos nacionais, diluiu-se a ténue partilha identitária do pós-guerra. Sem uma língua, história e cultura comuns e perante um processo de integração realizado à margem da participação e do escrutínio popular, não se tornava evidente qual a base substantiva capaz de agregar as novas gerações de europeus. O Tratado da União Europeia, o mesmo que criou o cidadão da União, testemunhou o fim do consenso tácito sobre uma Europa construída por elites e sofreu o primeiro de vários referendos negativos sobre o projeto. $\mathrm{O}$ alheamento dos europeus é evidente e o euroceticismo e antieuropeísmo são incontornáveis. Os europeus sentem a União cada vez mais como um espartilho ou, quando menos, como uma irrelevância para a sua vida. Em vez de 'allegiance' é o receio e a desconfiança que caracterizam a relação dos europeus e da União. A gestão das crises daí resultantes tem sido a barganha política - v.g. os regimes excecionais concedidos à Dinamarca e à Irlanda - ou o recuo - v.g. o destino do Tratado Constitucional após os referendos negativos da Holanda e da França. O projeto europeu acaba por regressar ao 'business as usual'.

O relançamento da dinâmica da integração com a grandiloquente ambição de tornar o espaço europeu no mais dinâmico espaço mundial tem-se pautado pelo desenvolvimento de quadros flexíveis de coordenação da diversidade política. À Estratégia de Lisboa sucedeu o atual Horizonte 2020, articulando os tradicionais instrumentos estruturais financeiros com planos de crescimento assentes na inovação e no conhecimento cujos resultados são pouco visíveis. Entre os instrumentos privilegiados deste modelo flexível esteve o Método Aberto de Coordenação implementado no emprego e no Espaço Europeu de Ensino Superior. 


\subsection{O fim da ordem internacional bipolar, a construção de uma política externa e a heterogeneidade dos desafios externos}

A chegada da década de 90 foi um tempo de esperança e temor. O retorno do centro e leste europeu à Europa representava a viabilidade do sonho de uma 'casa comum europeia', mas acarretava igualmente a incerteza sobre os óbvios desafios da gestão da heterogeneidade, económica, é claro, mas sobretudo política. Era preciso agarrar a renovada Alemanha unificada ao projeto europeu com uma moeda única em preparação; era necessário afirmar a Europa como protagonista político internacional; era ainda indispensável ter um quadro político comum para a certa receção às novas democracias europeias. O projeto de união política ganhou fôlego a par da união monetária e no Tratado de Maastricht institui-se uma Política Externa e de Segurança Comum.

Porém, esta nova dimensão do projeto europeu não conseguiu iludir as políticas externas e interesses nacionais não apenas diversos, mas frequentemente divergentes. No imediato, testemunhamos o fracasso da União na guerra dos Balcãs. A complexa história europeia construída em séculos de rivalidades e alianças reapareceu e parece cada vez mais difícil descortinar uma solução consistente, como se vê na incapacidade para definir uma resposta política capaz para a vizinhança no sul e no leste. A falta de clareza e de capacidade de influência decisiva tem sido colmatada por múltiplos instrumentos jurídicos de diálogo político, de cooperação económica e de apoio financeiro - v.g a Parceria Mediterrânica ou a Parceria Oriental.

A PESC tem como objetivo o fortalecimento da identidade europeia $^{13}$, mas a sua natureza intergovernamental, a preservação das políticas externas nacionais e a ênfase na sua concertação traduzem

13 Cf. Preâmbulo do TUE. 
um intrínseco limite ${ }^{14}$. A realidade tem demonstrado a sua debilidade. A pretensão de apresentar uma voz internacional unitária respeitada é praticamente um 'whishful thinking'. A divisão aberta ou camuflada entre os EM que se repete em questões internacionais próximas e distantes comprova-o. Será ausência de vontade ou fruto de vontades heterogéneas, ditadas por realidades e interesses diversos? Não é evidente sequer que os interesses nacionais tenham sido reforçados pela debilidade do poder europeu. Na gestão das principais crises internacionais, a intervenção dos Estados europeus não só não apresenta a devida dimensão europeia, como simplesmente acompanha os EUA - v.g. a recente negociação com o Irão ou o combate ao Estado Islâmico -, não se impõe autonomamente. O recente agudizar da relação com a Rússia e da situação no sul do Mediterrâneo e no Próximo Oriente comprova as fragilidades da pretensa potência normativa que a União Europeia deseja ser.

\section{A unidade na identidade nacional e a identidade europeia} da diversidade - uma politeia institucionalmente precária e limitada estruturada no consenso e diferenciação

A unidade política europeia reconduz-se a uma politeia sui generis, nem estadual, nem intergovernamental, nem supranacional. As várias propostas de qualificação, tradicionais ou novas, iluminam algumas faces do complexo poliedro em dinâmica permanente, mas não a totalidade.

A separação de poderes presente no triângulo institucional Conselho/PE/Comissão é heterodoxa e precária. Além da limitação do poder central, assistimos à repartição do(s) poder(es) entre múltiplas sedes centrais - Presidente do Conselho Europeu; Presidência

14 Vide $\operatorname{artigo} 24 .^{\circ},{ }^{\circ}{ }^{\circ} 3, \S 2$, $\operatorname{artigo} 32 .^{\circ}$, artigo $34 .^{\circ}$ e $\operatorname{artigo~} 35 .^{\circ}$, do TUE. 
estadual do Conselho; Alto Representante; Presidente da Comissão Europeia; Presidência do BCE. O resultado de uma gestão com tantos protagonistas é muitas vezes cacofónico.

A unidade não é supranacional, e quando consegue existir, é simplesmente transnacional. Assenta em consensos limitados, construídos arduamente em negociações que rapidamente traduzem um 'downgrading' dos objetivos e das ambições iniciais. A Europa política não tem sido sequer subsidiária, mas simplesmente secundária, uma fórmula bizantina incapaz de impedir a progressiva irrelevância global do continente europeu.

Muitas vezes tem-se iludido que a diversidade é um verdadeiro 'constituinte ontogénico' da unidade europeia. Ao contrário do que sucedeu no processo de construção da identidade dos Estadosnacionais, onde houve uma homogeneização na esfera de jurisdição do Estado, na UE a substância da identidade é a diversidade. A unidade política é plurinacional e a identidade nacional é uma variável independente que qualquer equação política e jurídica europeia tem de integrar. Consubstanciam-se em múltiplos planos o respeito e a garantia da identidade nacional dos Estados membros: a subsidiariedade, a cidadania como vínculo derivado e não substitutivo, a administração indireta, até as simples competências de apoio em diversos domínios.

O conceito de 'identidade nacional' ganhou uma relevância jurídica autónoma (Nabli, 2012: p. 211) no Tratado de Lisboa ${ }^{15}$. $O$ conceito de identidade nacional reconhecido no TUE parece ser o reduto último e inalienável da soberania e da autonomia política e jurídica dos EM. Assim, mais do que conjunto de referências de representação coletiva transubjetivas, é sobretudo nas suas variáveis jurídicas constitucionais que alcança e condiciona a integração europeia (Nabli, 2012: pp. 211-212). Implica o respeito pela autonomia

15 Artigo $4 .^{\circ}$, n. ${ }^{\circ} 2$ do TUE. 
de organização político-jurídica dos $\mathrm{EM}^{16}$, tal como determinada pela Constituição $^{17}$, e obriga a União a uma posição de neutralidade a esse respeito (Nabli, 2012:212). Pode ter dimensões materiais consubstanciadas em objetivos legítimos, como o respeito pela dignidade humana $^{18}$ ou a diversidade cultural e linguística ${ }^{19}$.

É um fundamento para uma acomodação e derrogação ao regime jurídico comum definido na União e é um limite a princípios como o primado e o efeito direto na jurisprudência constitucional em vários $\mathrm{EM}^{20}$, sendo a sua última manifestação a pronúncia do Tribunal Constitucional alemão sobre o Tratado de Lisboa ${ }^{21}$. Aqui se referiu a 'identidade constitucional' como um limite à integração europeia, indissociável da democracia e envolvendo domínios como a cidadania, a organização da segurança civil e militar, os direitos fundamentais $^{22}$. O artigo $8 .^{\circ}$, n. $^{\circ} 4$ da Constituição portuguesa plasma

16 Acórdão de 4.3.2004, RFA c. Comissão, Proc. C-344/01.

17 Em alguns EM importam mesmo limites materiais de revisão constitucional (v.g. o art. 79.3 da Constituição de Bona, que consagra o designado 'princípio federativo', ou a 'forma republicana de governo' salvaguardada pelo artigo 89.5 da Constituição francesa'). O TJ conferiu relevo a consequências decorrentes da forma republicana de governo como elemento da identidade constitucional no caso Sayn-Wittgenstein (Acordão de 22.12.2010, Proc. C-208/09). A especial atenção à autonomia local e regional já anteriormente à sua inclusão na identidade nacional era objeto de reconhecimento para 'modelar' a apreciação do cumprimento do direito comunitário. Cf. Acórdão de 6.9.2009, Portugal c. Comissão, Proc. C-88/03; Acórdão de 11.9.2008, UGT-Rioja, Procs. Ap. C-428 a 434/06; Acórdão de 16.7.2009, Horvath, Proc. C-428/07.

18 A Alemanha invoca este fundamento específico integrante da 'identidade constitucional alemã' para a restrição da livre prestação de serviços e que o TJ aceitou como legítimo. Cf. Acórdão de 14.04.2004, Omega, Proc. C-36/02.

19 Acórdão de 12.05.2011, Malgožata Runevič-Vardyn, Proc. C-391/09.

20 A existência de um reduto constitucional inalienável estava implícita em vários arestos dos tribunais constitucionais a propósito das pretensões de primazia do direito comunitário (v.g. a conhecida 'Decisão Solange I', BVerfGE 37, 271, de 29.05.1974, do Tribunal Constitucional alemão; ou a Decisão a 'Decisão Frontini', causa 183/73, do Tribunal Constitucional italiano).

21 Cf. BverfGE, II Senat, 30.06.2009, 2 BvE 5108.

22 Cf. BverfGE, II Senat, 30.06.2009, 2 BvE 5108, § 249. Em França, também o Conselho Constitucional já tinha, em 2006, entendido haver uma 'identidade constitucional francesa'. Cf. Decisão ${ }^{\circ}$ 2006-540 DC, de 27.07.2006, cons. 19. Consultada a 22.11.2015 em http://www.conseil-constitutionnel.fr/conseil-constitutionnel/francais/ 
uma orientação semelhante. A identidade nacional não confronta a pretensão de primazia do direito da União com a existencial superioridade formal das constituições, mas aponta um limite material fundamental de natureza constitucional integrado por um conjunto variável de valores, princípios e direitos, irredutível e de respeito imperativo para o direito da União.

A identidade nacional apresenta-se como um valor modelador da aplicação das normas da União e como um elemento de modelação interpretativa dessas normas ${ }^{23}$. Potencialmente, pode contribuir para uma 'recomposição da governação' da União, impondo um novo equilíbrio entre os fins legitimamente prosseguidos pelos EM e pela União, mais do que um limite à intervenção desta. Por isso, os princípios gerais de direito comunitário podem e devem, em certas situações, ser diversos e não uniformes. A integração e os interesses da União e do seu direito não têm um valor superior se não provarem que efetivamente o merecem e lhes é devido, pela respetiva bondade para os interesses dos cidadãos europeus na generalidade, e não como absolutos princípios abstratos, como se fossem uma nova 'raison d' État', sob novas vestes, com legitimidade para submeter tudo e todos. A definição desse equilíbrio é uma construção dinâmica que envolve o diálogo multinível entre os EM e a União ${ }^{24}$, nomeadamente entre o TJ e as jurisdições nacionais.

les-decisions/acces-par-date/decisions-depuis-1959/2006/2006-540-dc/decision-n-2006-540-dc-du-27-juillet-2006.1011.html. Nesta se incluiriam a laicidade do Estado, o direito de greve, o princípio da continuidade do serviço público.

${ }^{23}$ Esse é o relevo dos atos que respondem às exigências irlandesas e checas apresentadas a propósito do Tratado de Lisboa. Cf. Conclusões da Presidência, Conselho Europeu de 11 e 12.12.2008, e Conclusões da Presidência, Conselho Europeu de 29 e 30.10.2009, respetivamente. Consultadas a 22.11.2015, em https://infoeuropa. eurocid.pt/registo/000042772/documento/0001/ e em https://infoeuropa.eurocid.pt/ registo/000041518/documento/0001/

${ }^{24}$ Este é mais um indício de uma recomposição que aprofunda a relevância dos EM no desenvolvimento da União, a par, por exemplo, da participação dos parlamentos nacionais no procedimento legislativo prevista desde o Tratado de Lisboa 
Já foi proposta a consagração no tratado de um princípio do respeito pela identidade nacional, que acolheria diversas manifestações: a organização política interna, a ordem jurídica autónoma, as respetivas manifestações culturais (Mattera, 2002: 220-222). Este seria um princípio jurídico garantia, a par de outros como a subsidiariedade, e um princípio jurídico constituinte.

Nesta perspetiva, a heterogeneidade das preferências políticas não é necessariamente negativa; pelo contrário, a União tem de conviver com ela na medida em que é manifestação de opções legitimadas democraticamente pelas comunidades estaduais e o respeito pela democracia e identidade nacionais são princípios fundamentais da União. As preferências políticas e sociais dos EM não podem ser encaradas como escolhos a desprezar. São manifestação da legitimidade política subjacente à sua definição, e que não tem um substituto ainda a nível europeu, ou são manifestação de uma identidade cultural, histórica, etc., que merecem tutela jurídica e que não podem ser simplesmente marginalizadas em ordem a um interesse europeu 'abstrato', não mobilizador e a-identitário.

O interesse europeu, mesmo que consagrado no tratado, tem de ser interpretado e definido, não isoladamente, mas em interação e diálogo permanente com aqueles elementos. Foi um desacordo fundamental quanto às preferências políticas principais da integração que conduziu aos grandes momentos de diferenciação constitucional, desde a Carta dos Direitos Sociais, de 1989, passando pela UEM, até à CDF e ao Tratado de Lisboa, em 2007 (Majone, 2008, 465). Estes desacordos fundamentais não encontram a solução adequada nas simples fórmulas derivadas de diferenciação como a cooperação reforçada ou as derrogações. Exigem uma diferenciação 'consti-

(Protocolo relativo ao papel dos Parlamentos nacionais na União Europeia; Protocolo Relativo à aplicação dos Princípios da Subsidiariedade e da Proporcionalidade). 
tucional', pois têm que ver com o pacto fundador da União, que, sendo jurídico, é, em primeira linha, político.

As fórmulas derivadas, como as cooperações reforçadas, inserem-se na mesma linha de justificação, mas não dizem respeito a opções substantivas consideradas como politicamente fundamentais para os Estados. Podem ter mais a ver com o método prosseguido, com o momento e com opções políticas 'conjunturais', ou com especificidades que determinam o não acompanhamento de uma iniciativa.

Assim, há que reconsiderar teoricamente a unidade. A unidade constitui-se sobre a diversidade, não anulando-a, antes contruindo-se com ela e através dela. A unidade vai a par com a diversidade e o reconhecimento da identidade nacional. A unidade e a diversidade não são dois polos opostos, entre os quais há que buscar o equilíbrio; são antes duas contrafaces da integração que não podem existir isoladas, mas acompanham-se necessariamente, ambas confluindo (e não cruzando, porque não têm sentidos opostos) para a integração europeia, uma integração europeia com correspondência na realidade europeia diversa.

A diversidade e a identidade nacionais, quando se refiram a domínios políticos estruturantes ou a valores fundamentais podem implicar uma diferenciação estrutural-constitucional (v.g. os 'opt-out' da Dinamarca e Reino Unido, Irlanda e até da Polónia). Quando a diversidade e a identidade se manifestem em exigências específicas legítimas de alcance inferior podem, consoante o seu fundamento objetivo ou voluntário, ser acomodados pelas derrogações, pelas cooperações reforçadas ou por uma 'flexibilidade' interpretativa e aplicativa do direito da União.

O consenso é outra das suas manifestações. Em situações de diversidade inicial, o consenso impõe-se como uma condição essencial nos pactos iniciais. Só ele pode fixar um conjunto de princípios fundamentais e estruturantes, substanciais e adjetivos que legitimam depois outras formas mais simplificadas de deliberação 
(Puy-Muñoz, 2002: 184-185). Esta tem sido a lógica fundamental do processo de integração europeia, com os tratados e as respetivas revisões, onde se fixam os tais elementos, sujeitos ao requisito do acordo entre todos.

Mais, na União deparamo-nos, além dos procedimentos formais previstos, com práticas instituídas de modo mais ou menos formal, mas à margem daqueles, e que podemos reconduzir a 'convenções constitucionais' ou 'praxes constitucionais'. São, na realidade, tão importantes como os textos formais. São mais uma forma de flexibilidade, de que é exemplo o consenso como 'prática decisional' que perdurou durante décadas (e que, mitigada, ainda se encontra presente no funcionamento do Conselho). A negociação permanente e o empenho em soluções que acomodem as múltiplas exigências presentes - v.g. o 'package deal' - são intrínsecos ao funcionamento das instituições da União. O consensualismo é uma acomodação discursiva e substantiva dos diferentes argumentos, interesses e valores capaz de ser um jogo de soma positiva (Puy-Muñoz, 2002: 171) em sociedades não homogéneas. É mais importante ainda quando o sistema depende, no seu desenvolvimento e efetivação, das esferas nacionais, como sucede na União ${ }^{25}$. A permanente reconfiguração das convenções constitucionais acordadas é um traço estruturante, a inconclusão é uma possibilidade e a flexibilidade sob formas diferenciadoras pode ser a solução (Tully, 1995).

Ainda que a identidade e a vontade jurídica da União sejam próprias e não se confundam com a mera soma das identidades e das vontades dos Estados, a identidade e vontade jurídica dos Estados não devem ser um mero elemento de facto, de simples 'power politics', mas devem ter uma relevância jurídica específica. $\mathrm{Na}$ verdade, são fundamentais na equação definidora do sistema

25 A execução do direito da União compete, em princípio, aos Estados-membros, de acordo com o artigo $291 .^{\circ}, \mathrm{n} .^{\circ} 1$ do TFUE). 
jurídico da União. A identidade e a diversidade, além de valores, devem ser consideradas como 'princípios de princípios', como princípios matriciais conformadores de outros.

Podem legitimar a submissão das normas de direito derivado e até originário a uma condicionalidade na respetiva aplicação, em atenção aos princípios fundamentais das Constituições dos EM, como os direitos fundamentais, a separação de poderes, o princípio da legalidade e o princípio da independência nacional. Quando tal conflito excecional suceda, deve admitir-se a não aplicação dessas normas de direito derivado, ou, para quaisquer normas, uma interpretação conforme à constituição, se possível, não por causa de uma primazia primacial da constituição (mais uma vez o raciocínio ortodoxo que só conhece o Direito como pirâmide normativa, que acaba por pôr em causa a primazia), mas porque essa norma atenta contra um princípio fundamental da constituição de um Estado. Este, não é apenas uma norma fundamental do Estado, mas integra também o sistema jurídico da União como elemento constitutivo de um valor fundamental da União que é a identidade nacional. Esse 'vício' não é absoluto, mas relativo, situado jurídico-espacialmente no território jurídico em que a sua aplicação tem de articular-se com o sistema nacional. O Tribunal de Justiça já assumiu essa flexibilidade 'modeladora/diferenciadora', nomeadamente através da cláusula de 'ordem pública'26. De iure constituendo, seria importante haver orientações definidas sobre esses 'princípios vitais, indispensáveis à manutenção da identidade constitucional, i.e. uma espécie de elenco de 'interesses vitais' como se fez para o compromisso do Luxemburgo ${ }^{27}$. Na ausência dessa definição, concretiza-se uma deferência casuística negociada aos interesses dos EM através da

26 Cf. Casos 'Omega' e 'Sayn Wittgenstein', cit.

$27 \mathrm{O}$ artigo $53 .^{\circ}$ da Carta dos Direitos Fundamentais admite essa abertura através da cláusula da 'melhor tutela'. 
diferenciação normativa direta, seja como derrogação ou isenção, seja através de avanços integradores em que nem todos participam.

Devem admitir-se outros 'princípios de princípios', entre os quais o princípio da integração, ou melhor, o princípio europeu, bem como outros, que são decorrentes deste, v.g. o princípio da livre circulação, o da não discriminação, o do reconhecimento mútuo, que desempenham uma função modeladora em sentido inverso. Impõem aos Estados a consideração dos valores e interesses da União, dos outros EM e, mais importante, dos cidadãos europeus, e não apenas dos seus nacionais. E devem estar presentes em outras sedes para além da judicial, pois devem ser objeto de uma atenção idêntica na formulação das políticas da União e nacionais, seja pela via da abstenção, seja de modo positivo. $\mathrm{O}$ artigo $7 .^{\circ}, \mathrm{n} .^{\circ} 5$ e 6 e o art. $8 .^{\circ},{ }^{\circ} .^{\circ} 3$ e 4 da CRP apontam, ambiguamente, é certo, esta via.

\section{Referências}

COMMISSION OF THE EUROPEAN COMMUNITIES (1992), Europe 1992. The overall challenge ('Cechinni Report'), SEC (88)524 final, Brussels, 13 April 1988. Consultado a 22.11.2015 em http://aei.pitt.edu/3813/1/3813.pdf

EUROPEAN COMMUNITIES (1970), Bulletin of the European Communities, Vol. 3, No. 1, January 1970

EUROPEAN COMMUNITIES (1973), Bulletin of the European Communities, N. ${ }^{\circ}$ 12, Décembre 1973

EUROPEAN COMMUNITIES (1993), Conclusões da Presidência. Consultado a 22.11.2015, em http://www.consilium.europa.eu/uedocs/cms_data/docs/pressdata/ pt/ec/72926.pdf

CONSElHO EUROPEU (2008), Conclusões da Presidência, Conselho Europeu de 11 e 12.12.2008. Consultadas a 22.11.2015, em https://infoeuropa.eurocid.pt/ registo/000042772/documento/0001/

CONSElHO EUROPEU (2009), Conclusões da Presidência, Conselho Europeu de 29 e 30.10.2009. Consultadas a 22.11.2015 em https://infoeuropa.eurocid.pt/ registo/000041518/documento/0001/

EUROPEAN PARLIAMENT, COUNCIL, COMMISSION (1997), Declaração Comum sobre a Democracia e Direitos Fundamentais, de 5/4/1977, JOCE C 103 de 27.4.1977, p. 1

MAJONE, Giandomenico (1998), La Communauté européenne: un État régulateur, Paris, Montchrestien 
MAJONE, Giandomenico (2008), "Unity on Diversity: European integration and the enlargement process", European Law Review, pp. 457-481.

MATTERA, Alfonso (2002), "L'Union européenne assure le respect des identités nationales, régionales et locales, en particulier par l'application et mise en oeuvre du principe de la reconnaissance mutuelle. Un article $12 \mathrm{~A}$ à introduire dans le futur traité?", Revue de Droit de l'Union Européenne, 2002, n. ${ }^{\circ}$ 2, pp. 217-239.

MILWARD, Alan S. (1992), The European Rescue of the Nation-State, London and New York, Routledge, 1992

PUY-MUÑOZ, Francisco (2002), "O tópico do Consenso", in L. F. Colaço Antunes (coord.), Colóquio Internacional Autoridade e Consenso, Coimbra, Almedina, pp. 161-193.

NABLI, Béligh (2012), "L'identité (constitutionnelle) nationale: limite à 1'Union européenne?", Revue du Marché Commun et de l'Union Européenne, n. ${ }^{\circ}$ 556, mars 2012, pp. 210-215

TINDEMANS, Leo (1976), European Union. Report by Mr Leo Tindemans, Prime Minister of Belgium, to the European Council, Bulletin of the European Communities, Supplement $1 / 76$

TULLY, James (1995), Strange Multiplicity: Constitutionalism in the Age of Diversity, Cambridge, Cambridge University Press

WEILER, Joseph H. H. (1982), Supranational law and the supranational system: legal and political process in the European Community, Florence, European University Institute, 1982

WERNER, Pierre (1970), Report to the Council and the Commission on the realisation by stages of economic and monetary union in the Community ('Werner Report'), Supplement to Bulletin of the European Communities, N. ${ }^{\circ} 11,1970$ 